\title{
9
}

\section{ESPAÑA Y REINO UNIDO, DOS ECONOMÍAS AVOCADAS A ENTENDERSE TRAS EL BREXIT}

El presente artículo hace un repaso histórico del comportamiento de las relaciones comerciales y de los flujos de inversión directa entre España y Reino Unido antes de que se produzca la salida del país británico de la Unión Europea, es decir, antes del brexit. A lo largo del artículo se podrá ver la importancia de mantener las relaciones comerciales y financieras entre ambos países tras el brexit, dada la estrecha relación y dependencia entre ambas economías. El momento de incertidumbre que ha provocado la activación del artículo 50 del Tratado de Lisboa está haciendo que las relaciones comerciales estén experimentando un leve descenso, pero a nivel de flujos de inversión no se traslada tal preocupación desde Reino Unido, pero sí que han mermado las inversiones directas españolas en las islas británicas. Por su parte, el turismo, apoyado en otros factores externos, parece no atender a las consecuencias del brexit.

Palabras clave: exportaciones, importaciones, IDE (inversión directa extranjera), España, Reino Unido, turismo, brexit.

Clasificación JEL: F14, F21, F43, L83.

\section{Introducción}

Las relaciones comerciales entre España y Reino Unido se caracterizan por ser buenas, intensas y fluidas dentro de un marco bilateral de relaciones, estando actualmente influenciadas por la incertidumbre del brexit y sus previsibles consecuencias. En 2016, España fue el noveno país exportador de Reino Unido y el octavo importador, mientras que a nivel de inversiones España es también el noveno inversor más importante en el país británico.

\footnotetext{
* Departamento de Ciencias Empresariales de la Universidad Internacional de Valencia.

Versión de abril de 2018.
}

Sin lugar a dudas, una de las incertidumbres más importantes, que habita tanto en los países de la Unión Europea como en España en particular, son las consecuencias económicas de la salida de Reino Unido. De acuerdo con datos oficiales del propio Gobierno británico, el coste para Reino Unido de salir de la Unión Europea a corto plazo se contabiliza en una reducción del PIB de entre el 3,6 y el 6 por 100, mientras que a largo este porcentaje se sitúa entre el 3,8 y un 7,5 por 100. Por el lado europeo, el comisario responsable de Asuntos Económicos y Financieros de la UE, Pierre Moscovici, ha señalado que el impacto económico del brexit sobre el PIB, en el conjunto de los países de la UE-27, se situaría entre el 0,2 y el 0,5 por 100 . 
Todos los datos anteriores son simples previsiones que se han realizado bajo un nuevo marco de relaciones que puede no llegar a ser el que finalmente se implante, además de prever qué país establecerá el suyo con el país británico. La alta incertidumbre que está presente en las jornadas de negociación del proceso salida hace que sea muy difícil cuantificar el impacto real del brexit en España. A pesar de ello, en el presente artículo se presenta un análisis real de la situación de las relaciones comerciales y financieras entre España y Reino Unido, con el objetivo de mostrar el grado de exposición de nuestros sectores e inversiones económicas a las consecuencias del proceso del brexit.

\section{Teorías del comercio y de la internacionalización de la empresa}

Como al iniciar todo camino de investigación, el área de la estrategia empresarial y, más en concreto, el estudio de los procesos de internacionalización deben plantear una serie de preguntas que tienen que ser resueltas a medida que se profundiza en la investigación. Pues bien, desde los inicios de la ciencia económica del comercio, las preguntas objeto de respuesta han sido por qué, cuándo, dónde y cómo las empresas comprometen sus recursos en negocios internacionales. A pesar de que la mayoría de los trabajos que han dado lugar a teorías o a modelos de internacionalización han tenido como objetivo dar respuesta al por qué, el resto de preguntas se encuentran ligadas a la misma y, por consiguiente, en un mayor o menor número de trabajos ha sido objetivo de estudio también.

En el campo teórico, el escenario de la teoría de la administración de empresas ha estado dominado por teorías y modelos de base económica. A partir de estas teorías se ha desarrollado el estudio de los negocios internacionales, que lleva implícito en primer lugar el comercio internacional, y la internacionalización de las actividades empresariales en segundo lugar.

Los modelos tradicionales de comercio internacional resultan incompletos para explicar las causas de la inversión directa internacional, dado que bajo sus planteamientos de mercado perfectamente competitivos, sin fallos y con rendimientos constantes a escala, la posibilidad de obtener incrementos en los beneficios por aumentos en la producción desaparecería al no existir oportunidades de mejora de eficiencia. No obstante, la simple existencia de ventajas específicas para una empresa supone que las empresas multinacionales no se desenvuelven en un mundo competitivo (Caves, 1971). Por lo tanto, en el campo de la administración de empresas se ha convertido en una especie de dogma de fe el supuesto de mercados de competencia imperfecta (Graham, 1992) y con la existencia de fallos en los mismos.

Los estudios más importantes se pueden agrupar en una serie de teorías que recogen las principales aportaciones (Tabla 1) acerca de la internacionalización de las empresas: teoría del comercio internacional, teoría de la organización industrial, teoría del ciclo de vida del producto, teoría de la internacionalización y teoría del concepto de redes.

En los últimos años, debido a la repercusión de las nuevas tecnologías y de internet, se han desarrollado una serie de teorías que ponen en entredicho los supuestos de las clásicas mencionadas anteriormente. Destacamos dos de ellas que definen dos tipos de empresas: New Ventures \& Global Born.

La teoría (clásica) del comercio internacional nace bajo los postulados de Adam Smith $\triangleright$ 
TABLA 1

PRINCIPALES TEORÍAS INTERNACIONALES Y SUS AUTORES MÁS IMPORTANTES

\begin{tabular}{|c|c|}
\hline $\begin{array}{l}\text { Teoría clásica del } \\
\text { comercio internacional }\end{array}$ & Smith (1776), Ricardo (1817), Marshall (1879), Edgeworth (1894a, 1894b, 1894c) \\
\hline $\begin{array}{l}\text { Teoría neoclásica de la } \\
\text { ventaja comparativa }\end{array}$ & Heckscher (1919), Lerner (1932, 1934), Leontief (1933), Ohlin (1933), Haberler (1936), Meade (1952) \\
\hline $\begin{array}{l}\text { Escuela de Organización } \\
\text { Industrial }\end{array}$ & $\begin{array}{l}\text { Arrow (1962), Hymer (1960, 1976), Kindlerberger (1969), Johnson (1970), Caves }(1971,1974,1982) \text {, } \\
\text { Hirsch (1976) }\end{array}$ \\
\hline $\begin{array}{l}\text { Teoría de la } \\
\text { internalización }\end{array}$ & $\begin{array}{l}\text { Coase (1937), Williamson (1975), Buckley \& Casson }(1976,1979), \text { Rugman }(1981,1982 a), \text { Anderson } \\
\text { \& Gatignon (1986), Hennart \& Park (1993), Cantwell (1995) }\end{array}$ \\
\hline Teoría de los recursos & $\begin{array}{l}\text { Penrose (1959), Wernerfelt (1984), Teece, Pisano \& Shuen (1990), Barney (1991), Rugman \& } \\
\text { Verbecke (1992), Chandler \& Hanks (1994b), Caves (1996) }\end{array}$ \\
\hline $\begin{array}{l}\text { Teoría de las capacidades } \\
\text { organizacionales }\end{array}$ & $\begin{array}{l}\text { Penrose (1956), Teece (1982), Wernerfelt (1984), Kogut \& Zander (1993), Nonaka \& Takeuchi (1995), } \\
\text { Madhock (1997) }\end{array}$ \\
\hline Teoría de la localización & $\begin{array}{l}\text { Kojima (1976), Root \& Ahmed (1978, 1979), Owen (1982), Seymour (1987), Brooke \& Buckley (1988), } \\
\text { Cantwell (1988), Porter (1990), Ozawa (1992) }\end{array}$ \\
\hline $\begin{array}{l}\text { Teoría secuencial o de } \\
\text { procesos }\end{array}$ & $\begin{array}{l}\text { Vernon (1966), Knickerbacker (1973), Johanson \& Wiedersheim-Paul (1975), Johanson \& Vahlne } \\
\text { (1977), Root (1987), Cavusgil (1980, 1990), Plá \& Ortega }\end{array}$ \\
\hline Enfoque de la innovación & $\begin{array}{l}\text { Simmonds \& Smith (1968), Wind, Douglas \& Perlmutter (1973), Bilkey \& Tesar (1977), Lee \& Brasch } \\
\text { (1978), Czinkota (1982), Barlett \& Goshal (1991), Li (1994) }\end{array}$ \\
\hline Enfoque de la dirección & Gallo (1987), Calof \& Beamish (1995), Alonso \& Donoso (1996) \\
\hline Enfoque estratégico & $\begin{array}{l}\text { Levitt (1983), Kogut (1985), Porter (1985), Hamel \& Prahalad (1986, 1988), Aaby \& Slater (1989), } \\
\text { Alonso \& Donoso (1993), Root (1994), Welford \& Prescott (1994) }\end{array}$ \\
\hline $\begin{array}{l}\text { Enfoque de la } \\
\text { globalización }\end{array}$ & Porter (1982, 1986), Kim \& Hwang (1992), Casson (1993), Buckley (1995), Strategor (1995) \\
\hline Enfoque de redes & $\begin{array}{l}\text { Ford (1980), Casson (1986), Johanson \& Mattson (1988, 1992), Prahalad \& Hamel (1990), Miles \& } \\
\text { Snow (1996), Coviello \& McAuley (1999), Rialp (2005) }\end{array}$ \\
\hline $\begin{array}{l}\text { Teoría de las nuevas } \\
\text { empresas internacionales }\end{array}$ & $\begin{array}{l}\text { Oviatt \& McDougall (1994, 1999), Knight \& Cavusgil (1996, 2004), Madsen \& Servais (1997), Rialp } \\
\text { (2005), Bell \& McNauton (2000), Suárez \& Galván (2005) }\end{array}$ \\
\hline
\end{tabular}

(1776) plasmados en su obra La riqueza de las naciones. Esta primera aproximación al comercio internacional desde la perspectiva de la economía política clásica constituye la teoría de la ventaja absoluta. De acuerdo con la formulación original de Adam Smith, un país exportaría (importaría) aquellos bienes en las que tuviera ventaja (desventaja) absoluta de costes, es decir, aquellos bienes cuyo coste total de producción en términos absolutos fuera inferior (superior) en dicho país con respecto a los costes derivados de producir el mismo bien en otro país; ello además aportaría a la economía y a la sociedad de ambos países un incremento del bienestar. Esta ventaja absoluta se produce por la existencia en el país de una serie de factores como recursos naturales, trabajo, capital, tecnología... que les hace obtener una ventaja competitiva (absoluta) respecto a un tercer país.

Los planteamientos de Adam Smith fueron pronto reconsiderados dado el gran auge que el comercio internacional estaba teniendo. El autor más importante, que prosiguió los estudios del comercio internacional y dio una explicación al mismo hecho, fue David Ricardo (1817). Bajo una serie de supuestos (existen dos países y $\triangleright$ 
dos bienes; se cumple la teoría del valor trabajo; coste unitarios constantes; no existen costes de transportes ni aranceles), Ricardo desarrolló el principio básico de la teoría de la ventaja comparativa. Este postulado quiere decir que no hace falta que exista una ventaja absoluta o diferencias absolutas de costes para que aumente el bienestar de dos países que intercambien bienes mutuamente, sino que es suficiente que dichas diferencias de costes sean relativas.

La teoría clásica de la ventaja comparativa, anteriormente expuesta, se basa en la teoría del valor del trabajo, además de los tres supuestos. No obstante, la teoría del valor del trabajo ha sido siempre muy criticada debido a lo restrictivo de sus supuestos; en particular a que su validez requería que el trabajo fuese el único factor productivo empleado, que además fuera homogéneo (es decir, que todo trabajo debía ser de la misma calidad) y que existiera competencia perfecta entre los mismos trabajadores. Para resolver dicha limitación del planteamiento clásico, Marshall (1879) y Edgeworth (1894a, 1894b, 1894c) establecieron las bases para que más tarde Leontief (1933), Lerner (1932, 1934), Haberler (1936) y Meade (1952) desarrollaran una reformulación neoclásica de la teoría de la ventaja comparativa. Esta reformulación de la ventaja comparativa se realiza en términos de costes de oportunidad, de manera que los costes de producir un bien vengan dados, no por la cantidad de horas de trabajo que conlleva producirlos, sino por la producción alternativa a la que se renuncia para permitir la producción del bien en cuestión 1 .

Sin embargo, estos modelos tradicionales suponen una absoluta inmovilidad internacional de los factores productivos, por lo que en

Bajo, O. (1991). Teorías del Comercio Internacional. Antoni Bosch. realidad no pueden dar respuesta a los flujos financieros de inversión directa extranjera. Por ello Heckscher (1919) y Ohlin (1933) desarrollaron el modelo Heckscher-Ohlin ( $\mathrm{H}-\mathrm{O})$, que predice un patrón de comercio basado en las dotaciones relativas de factores de las distintas naciones y ofrece la primera justificación al desplazamiento internacional del capital de los países con grandes acumulaciones de capital hacia los países con abundante mano de obra. No obstante, se trata de desplazamientos indirectos a través de flujos de bienes, ya que los desplazamientos directos de los factores de producción solo tendrían cabida en el modelo $\mathrm{H}-\mathrm{O}$ en el caso de existir diferencias a nivel internacional en su remuneración. Pero movilidad perfecta de bienes y no igualación del precio de los factores son elementos incompatibles.

La rápida y extensa expansión de la globalización de las actividades económicas en las últimas décadas ha aumentado el amplio abanico de posibilidades de realizar actividades, ya sean productivas o de servicios, en el exterior, lo que ha hecho que las inversiones directas extranjeras repuntaran desde la década de 1990. La decisión de convertirse en una empresa internacional es una de las más importantes en la vida de una empresa. La elección del modo de entrada es una decisión estratégica que adopta el corporate de la empresa. Las empresas a la hora de internacionalizar sus actividades no solo atienden a qué mercados entrar, sino también tiene especial relevancia la forma bajo la cual la harán: exportación, contrato de licencia o inversión directa (Root, 1994). Dicha elección entre un tipo u otro tiene grandes consecuencias a nivel estratégico en la empresa (matriz).

De entre todas las teorías que tratan de explicar el proceso de internacionalización de las empresas multinacionales resalta, por encima $\triangleright$ 
de todas, el paradigma ecléctico de Dunning, aceptado como el modelo más completo hasta ahora desarrollado. Por ello, es la base de mi investigación. Aunque se haya explicado ya en este trabajo, vamos a resumir en qué consiste, partiendo de la premisa de que una empresa realizará actividades de valor añadido en el exterior si, y solo si, se satisfacen tres condiciones:

1. Posee ventajas específicas de propiedad (O) netas frente a firmas de otras nacionalidades para servir a un mercado específico. Subparadigma: a mayor ventaja competitiva de las empresas multinacionales frente a otras firmas, mayor propensión de las mismas a la inversión directa extranjera.

2. Dado lo anterior, sería más rentable para la empresa usar esa ventaja antes que venderla o licenciarla. La producción se realiza a través de la extensión de la cadena de valor existente, lo que resulta en una ventaja de internalización (I). Subparadigma: ofrece un marco para evaluar formas alternativas en las cuales las firmas organicen la generación y explotación de sus competencias centrales.

3. Dado 1 y 2 , debería ser de interés global de la empresa utilizar estas ventajas en conjunción con al menos algunos factores o insumos de fuera de su país de origen que hacen a las ventajas de localización (L). Subparadigma: cuantos más recursos inmóviles (naturales o creados) necesiten las empresas para desarrollar sus ventajas competitivas, mayor propensión a ubicar actividades de producción fuera de sus fronteras.

A la vista de las aportaciones de Buckley (1981), Rugman (1986), Casson (1987), Guisinger
(2001), Dimelis y Lowi (2002) y Pin Ho, Lin, S. y Lin, Y.C. (2010); de los trabajos empíricos de Anderson y Gatignon (1986), Agarwal y Ramaswami (1992), Erramilli y Rao (1983) y Kogut y Singh (1998), así como de los argumentos que yo mismo presento en esta investigación, del presente trabajo se puede llegar a la conclusión de que el paradigma ecléctico de Dunning puede ser extendido con el fin de ser más completo y real, acorde con los tiempos que estamos viviendo. Una de las situaciones que el modelo OLI no llega a explicar es la forma bajo la cual las empresas penetran (a través de IDE) en los nuevos mercados, ya que Dunning desarrolló el modelo bajo la perspectiva única de la filial.

Esta nueva variable, como se menciona en el párrafo superior, es la forma de entrada a nuevos mercados, representada por la letra $M$ (del inglés modes of entry). Bajo esta nueva variable, tengo en consideración la colaboración o cooperación entre empresas a la hora de hacer frente a una inversión en un entorno no doméstico, así como otros tipo de IDE bajo la dirección de la propia matriz, considerándose también estas como filiales. El paso que doy de extender el modelo OLI tiene su lógica, ya que una vez que has decidido que el país es adecuado para realizar la inversión, hay que elegir el modo bajo el cual se va a hacer efectiva dicha inversión. Dunning no contemplaba este paso, pues para él la única opción era la creación de una filial (productiva). Lo más parecido estratégicamente hablando a este punto que Dunning plantea es el porqué de la entrada en un nuevo mercado exterior, resumidos en: resource seeking, market seeking, efficient seeking y strategic asset seeking.

La complejidad, tanto del entorno micro como del macro de la empresa, ha ido aumentando con el paso del tiempo, por lo que es $\triangleright$ 


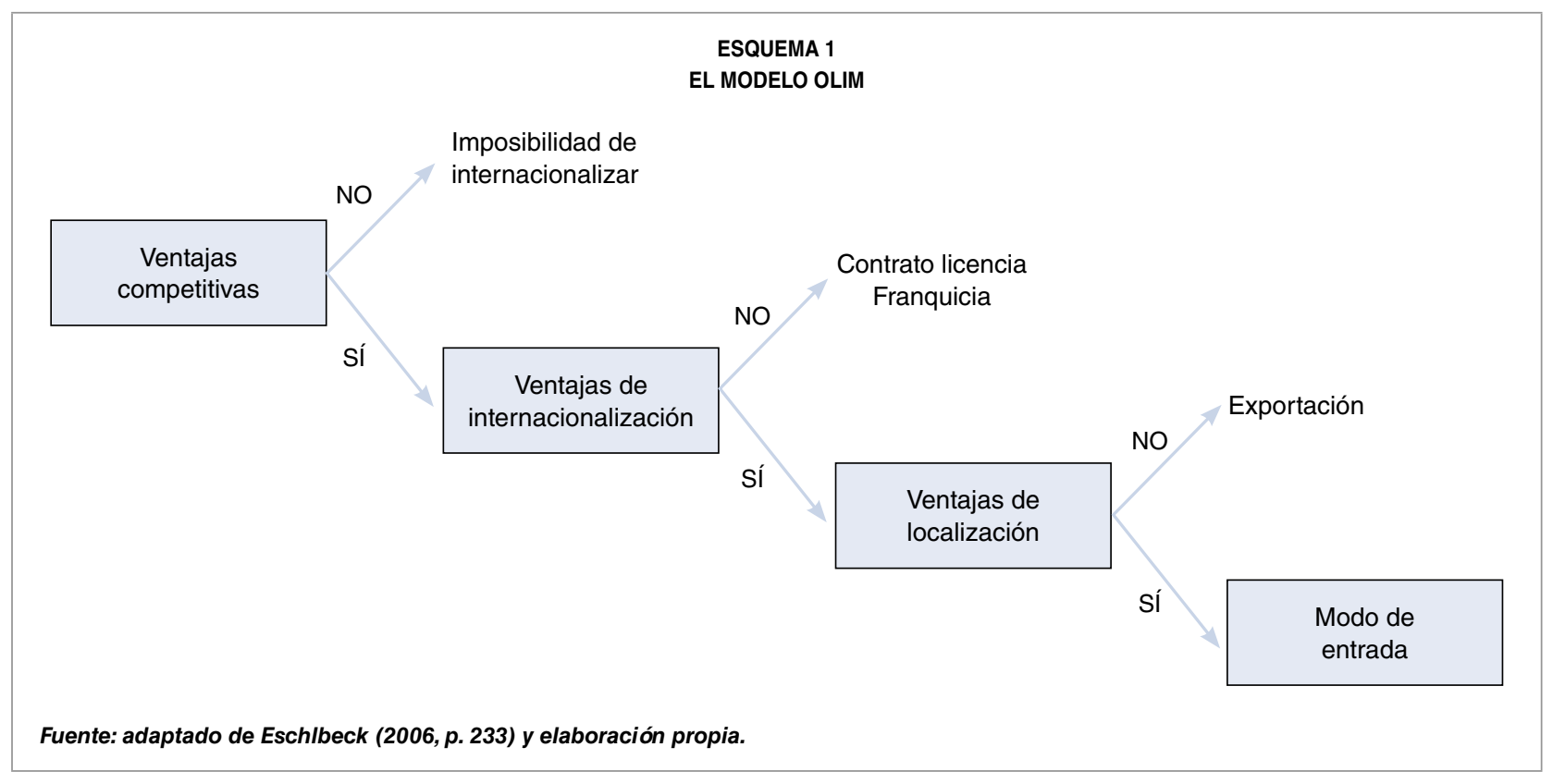

necesario, y por ello plasmo en este apartado, desde mi punto vista, un nuevo o más extendido planteamiento del proceso de internacionalización de la empresa, cosa que hago bajo mi «modelo OLIM». Se ha demostrado, tanto teórica como empíricamente a lo largo de las últimas décadas, que existen varias posibilidades de entrar en un mercado bajo inversión directa, ya sea a través de un crecimiento interno (filial propia) o de un crecimiento externo (alianzas con otros competidores). Esta realidad quiero plasmarla en el replanteamiento del paradigma ecléctico con la incorporación de la nueva variable de decisión «modos de entrada», como puede verse en el Esquema 1, que representa el modelo OLIM que defiendo.

\section{Características económicas de Reino Unido}

Cuando hablamos de Reino Unido lo hacemos sobre la sexta economía más grande del mundo en términos de PIB y la actual tercera economía de Europa, tan solo por detrás de
Alemania y Francia, cuyo crecimiento hizo que adelantase a la economía británica en el último trimestre de 2017. Esta posición de dominio económico, pero sobre todo de supremacía financiera, lo ha conseguido gracias a un desarrollo del sector servicios que acapara la mayor importancia de su PIB (el 75 por 100 del mis$\mathrm{mo}$ ), en el que destacan por encima de todo las finanzas, constituyéndose Londres como la segunda capital mundial de las mismas, solo por detrás de Nueva York.

Desde 2008, año en el que comenzó la última gran crisis financiera, su economía se ha afianzado como una de las potentes. A pesar de que el PIB se hubiera contraído durante los años 2008 y 2009, acumuló a finales de 2017 dieciséis trimestres consecutivos de crecimiento de su PIB, tanto en términos nominales como en precios corrientes, de acuerdo a un estudio elaborado por la Agencia Andaluza de Promoción Exterior. Actualmente, la situación política generada por el brexit ha hecho que el escenario sea incierto respecto hacia dónde va a evolucionar su PIB a corto y medio plazo, sin haber predicciones suficientemente fuertes $D$ 
para ver el impacto de la salida del Reino Unido de la Unión Europea.

Aunque actualmente la economía de Reino Unido se halle sumida en un cierto grado de incertidumbre, las cifras nos dicen que durante 2017 los cuatros sectores principales de su economía tuvieron un crecimiento positivo, con un cierto retroceso en un nivel de crecimiento a finales del año. En el empuje de esta tendencia positiva se encuentra en primer lugar el sector servicios, seguida por las actividades comerciales o de distribución y la hostelería. El sector agrícola, a pesar de no aportar mucho al PIB, creció también durante 2017, mientras que la industria manufacturera y la construcción experimentaron sendos retrocesos de su actividad, al igual que la distribución minorista, según fuentes de Eurostat. Estos buenos resultados logran esconder una serie de fragilidades y puntos débiles de la economía de Reino Unido, como pone en relieve un estudio elaborado por Santander Trade. En el mismo se destaca que el crecimiento experimentado durante 2017 ha sido como consecuencia del consumo interno, habiendo descensos en el nivel de la inversión recibida, así como de las exportaciones, sobre todo a países europeos. El crecimiento está basado en salarios bajos y en el incremento del trabajo precario, aumentando el trabajo a su vez de trabajadores freelance y de trabajadores con contratos que no llegan al número mínimo de horas trabajadas para contar con cobertura social.

En lo que se refiere al nivel de precios, el IPC interanual del Reino Unido creció durante 2017 debido a subidas, entre otros, de los precios de la ropa y de los combustibles, con cotas que llegaron al 2,9 por 100 en julio y agosto. En esta dinámica todavía no está registrado el posible efecto de la depreciación de la libra como consecuencia de la inminente salida del Reino Unido de la Unión Europea, por lo que el brexit influirá inevitablemente en el nivel de precios de los productos importados, estimulando un crecimiento de los mismos. Para una gran variedad de productos ingleses, durante 2017 se vieron incrementados sus precios siguiendo la tendencia iniciada en el cuarto trimestre de 2016, siendo superior que el crecimiento experimentado por los países más occidentales de la Unión Europea. ¿Cuáles fueron los productos que más vieron incrementados sus precios? La ropa, el calzado, el mobiliario, los bienes de hogar, restaurantes y hoteles fueron los productos y/o servicios más inflacionistas.

En lo que se refiere al mercado de trabajo (según datos de julio 2017 proporcionados por la Oficina de Estadísticas británica), este se caracteriza por una tasa de ocupación registrada en el 75,3 por 100 , con un nivel de desempleo del 4,3 por 100 (la más baja desde que hay registros oficiales) y un número de empleados autónomos que llegó a la cifra de 4.850.000, representando el 15,1 por 100 del total de la población ocupada. Estos datos son ligeramente mejores que los registrados durante 2016, lo que sigue la línea de mejora económica que marca la evolución del PIB. Por otro lado, la tasa de inactividad (personas con edades comprendidas entre los 16 y 64 años en edad de trabajar) fue del 21,2 por 100 , representando un descenso del 0,4 por 100 respecto al mismo trimestre de 2016, siendo también la tasa más baja desde 1971, año en el que se realizan este tipo de registros. Desde la propia Oficina de Estadísticas británica se hace hincapié en que los salarios semanales de los empleados crecieron durante 2017 un 2,1 por 100 más en comparación con 2016, hablando en términos nominales. Si se acomete la aproximación desde términos reales, vemos que los salarios semanales sufrieron un descenso del 0,4 por 100 en 2017 respecto a 2016. 
Para finalizar este bloque, nos adentraremos en el análisis del estado de las cuentas públicas, basándonos en datos ofrecidos por la Oficina de Responsabilidad Presupuestaria y por el Comité de Política Monetaria del Banco de Inglaterra. Según el primer organismo, el endeudamiento neto del sector público descendió durante el año 2017 en 100 millones de libras, hasta alcanzar un stock de 28.200 millones de libras, representando el nivel de endeudamiento más bajo desde antes del inicio de la crisis en 2007. Del mismo modo, se ha previsto que el endeudamiento público para 2018 sea de 58.300 millones de libras. Por otro lado, en lo que se refiere a la deuda pública neta, la entidad registró una deuda de 1.617 millones de libras a finales del mes de agosto de 2017, habiendo sido excluidos del cálculo tanto el Banco de Inglaterra como los bancos del sector público. Este nivel de deuda representa el 80,3 por 100 del PIB británico. Por último, echando un vistazo a los datos publicados por el Comité de Política Monetaria del Banco de Inglaterra, el IPC se situó en septiembre de 2017 en el -0,1 por 100, habiendo una desviación, respecto a lo previsto, que incidía fundamentalmente en la caída de los precios de la energía, alimentos y productos importados. Esto ha hecho que el propio comité haya empezado a implementar una política monetaria estimulante, con el fin de propulsar el crecimiento, permaneciendo estables los tipos de interés en el 0,5 por 100, para lograr el objetivo de inflación del 2 por 100, firmado por la institución en noviembre de 2015.

\section{Relaciones comerciales bilaterales antes del brexit}

De acuerdo con el informe de KPMG, La empresa española ante el brexit, el 45 por 100 de las empresas que formaron parte del estudio afirmaron tener algún tipo de exposición a Reino Unido ante el próximo brexit, siendo las exportaciones la relación bilateral más común entre empresas de ambos países (16 por 100 de las empresas que afirman tener algún tipo de exposición ante la salida del Reino Unido de la UE), destacando los sectores de la automoción (65 por 100), el industrial y químico (64 por 100) y el de turismo y ocio (63 por 100).

\subsection{Relaciones comerciales de bienes}

Desde que se tienen datos oficiales de estadísticas del comercio exterior nacionales procedentes del actual Ministerio de Industria, Comercio y Turismo, las exportaciones de bienes y servicios hacia el Reino Unido han tenido una constante de crecimiento solo frenada por la crisis financiera durante el periodo 2008-2010.

Como puede contemplarse en el Gráfico 1, Reino Unido representa para España el tercer país importador de productos, solo por detrás de Alemania y Francia, siendo uno de los principales socios europeos de Reino Unido. De acuerdo con los datos oficiales de UK Trade Statistic Bulletin (ONS), las exportaciones de bienes y servicios de Reino Unido alcanzaron en 2016 la cifra de 669.866 millones de euros, un 5,8 por 100 mejor que en 2015 , mientras que sus importaciones totales lograron alcanzar la cifra de 751.154 millones de euros (un 6,8 por 100 más que en 2015), siendo España el octavo país proveedor de bienes y servicios de Reino Unido. Durante 2016, la Unión Europea se convirtió en el principal socio comercial por delante de China, situándose Alemania como principal socio comercial, por delante de Francia, Países Bajos e Irlanda. $\triangleright$ 




En el año 2016 se alcanzó la cifra máxima de exportaciones españolas hacia territorio británico, llegando a la cifra de 20.076.727,3 euros, siendo este el año de inflexión tras la decisión del Gobierno y de la población del Reino Unido de desmarcarse de la política europea común y decidir su salida de la Unión Europea, lo que se ha denominado el brexit. Por el lado contrario, las exportaciones británicas tuvieron la misma tendencia alcista hasta 2007, pero en comparación con las exportaciones españolas hacia Reino Unido la recuperación nunca ha llegado a ser tan fuerte, como se visualiza en el Gráfico 2. Las importaciones españolas procedentes del Reino Unido se han establecido en niveles de la última década del siglo pasado y aunque en 2013 pareció que iban de nuevo a cobrar fuerza, en 2016 rebotó dicha recuperación hacia otra tendencia negativa, tendencia que se mantiene tras la decisión del brexit.

En lo que se refiere a las exportaciones, los bienes con origen España y destino Reino Unido han tenido un gran repunte en el periodo 2010-2016, experimentando una tasa de crecimiento superior al 10 por 100 , representando alrededor del 8 por 100 de las exportaciones españolas y superando a Italia como tercer destino de los bienes y servicios españoles. En lo que llevamos de década, el sector del automóvil ha sido el motor de las exportaciones españolas hacia las islas británicas, representando una cuota del 27 por 100. Por otro lado, las importaciones procedentes de Reino Unido, a pesar de mantener una tónica de crecimiento hasta la crisis de 2008, no ha podido recuperarse, como así han hecho las exportaciones, por lo cual hace que el saldo de la balanza comercial de $D$ 
David de Matías Batalla

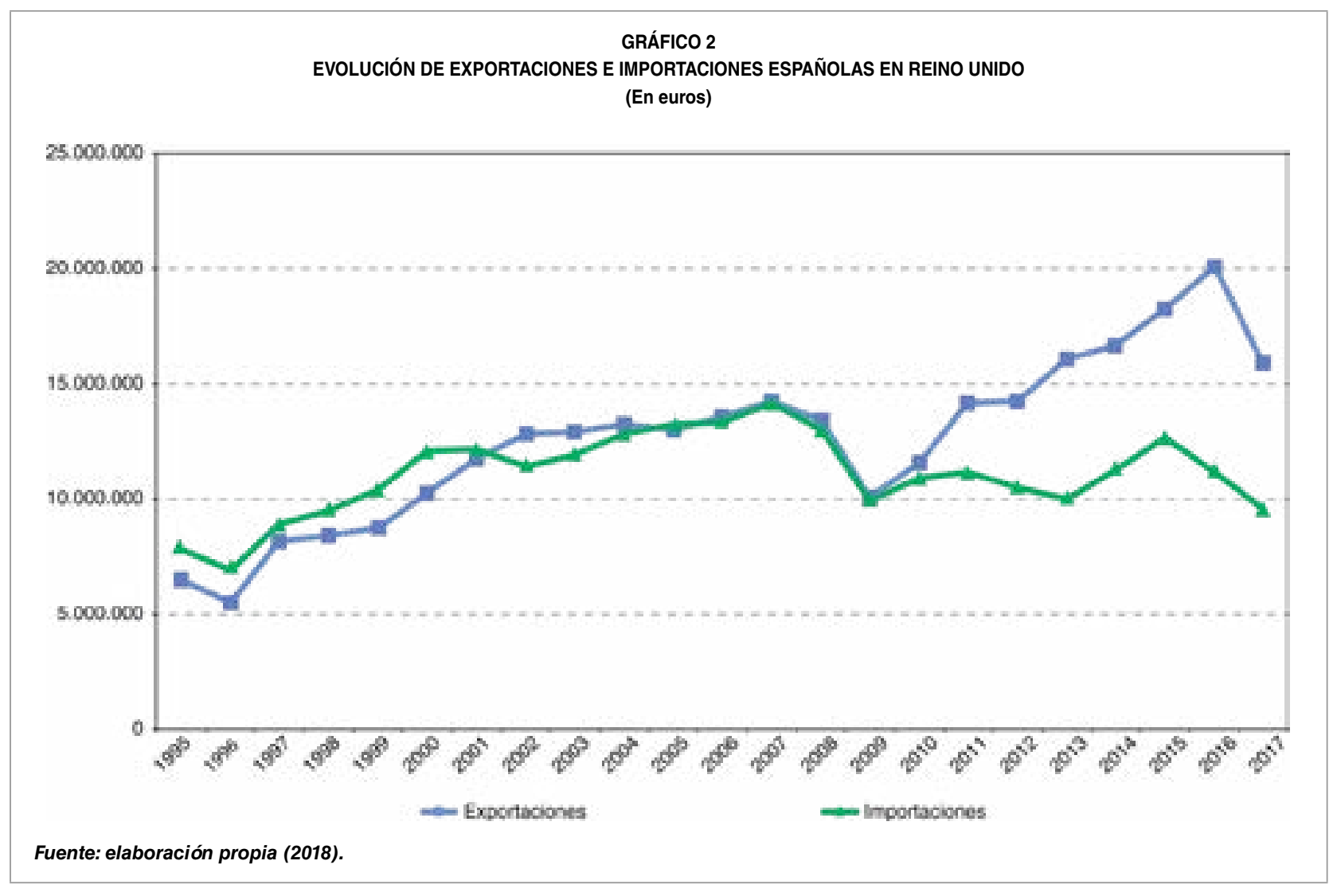

España con el Reino Unido sea positiva. Este superávit comercial con el Reino Unido que tie(representando el 1,3 por 100 del PIB) en 2015, ne España asciende a 1.049 millones de euros según la Encuesta de Comercio Internacional de Servicios (ECIS), realizada por el INE. $\quad \square$

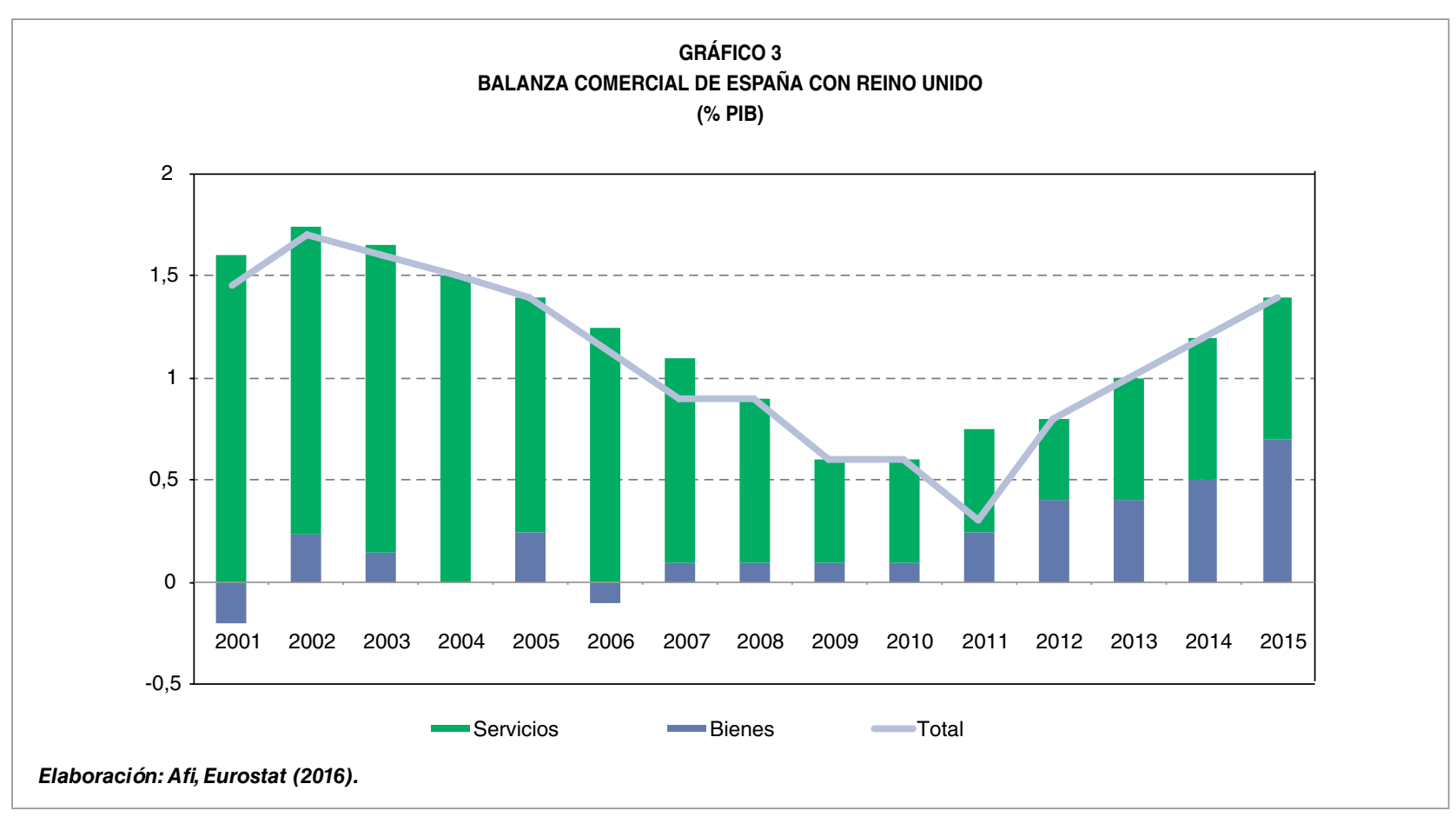


Si nos adentramos en la balanza de pagos por servicios a partir de los datos proporcionados por Statistical Bulletin, nos podemos dar cuenta de que las exportaciones de servicios en 2016 se incrementaron en un 7,1 por 100 en comparación con 2015, alcanzando los 301.158 millones de euros, siendo la principal partida de exportación otros servicios prestados a empresa, por valor de 89.079 millones de euros (13,4 por 100 más que en 2015), por delante de las partidas de servicios financieros (67.891 millones de euros) y viajes (27.841 millones de euros).

Precisamente, la partida contable viajes tiene un gran peso en las exportaciones totales españolas al Reino Unido con motivo del turismo (recordemos que Reino Unido es el principal país de origen de los turistas que visitan España). En 2016, el gasto de los residentes en Reino Unido durante el periodo vacacional en España aumentó en un 12 por 100 en relación con 2015, siguiendo la tendencia positiva que apuntan las fuentes económicas oficiales de España, Reino Unido y Europa. Entre los hechos más significativos a este aspecto cabe destacar que después de la crisis de 2008 aumenta el crecimiento de turistas independientes, el uso de internet para la contratación y organización de los viajes y la contratación de aerolíneas de bajo coste para realizar los vuelos.

\subsection{Relaciones comerciales por CCAA}

Si revisamos los datos por comunidades autónomas, los mismos se encuentran en línea con las estadísticas nacionales si estudiamos el total de las exportaciones e importaciones españolas, aunque existen algunas diferencias. Por un lado, Cataluña encabeza las exportaciones españolas de bienes y servicios hacia el Reino Unido con 63.013.963 miles de euros, seguida por Comunitat Valenciana (43.325.367 miles de euros), la Comunidad de Madrid (35.771.587 miles de euros), Andalucía (27.320.336 miles de euros) y País Vasco (23.625.326 miles de euros). A nivel relativo, comparando estos datos con las cifras totales de cada comunidad y el impacto de las mismas sobre sus economías, en línea con el BBVA Research, la comunidad autónoma más expuesta al brexit es Canarias, ya que concentra el 25 por 100 de sus exportaciones hacia el país anglosajón procedentes de sus ingresos por turismo, seguida de Cataluña (21 por 100 del total de sus exportaciones), donde sectores como el del automóvil, aparatos mecánicos y electrónicos, frutas y hortalizas y fármacos canalizan más de 10.000 millones de euros en exportaciones. Tras Canarias y Cataluña, el mayor $\triangleright$

TABLA 2

EXPORTACIONES E IMPORTACIONES ESPAÑOLAS CON REINO UNIDO POR CCAA

(Miles de euros)

\begin{tabular}{|c|c|c|}
\hline $\begin{array}{c}\text { Comunidades } \\
\text { autónomas }\end{array}$ & Exportaciones & Importaciones \\
\hline Andalucía . & $27.320 .336,17$ & $13.007 .232,45$ \\
\hline Aragón & $19.687 .276,57$ & $7.668 .441,91$ \\
\hline Asturias & $3.853 .827,85$ & $2.271 .349,73$ \\
\hline Balears, Illes & $1.793 .182,33$ & $2.405 .665,10$ \\
\hline Canarias & $1.951 .400,00$ & $4.614 .488,93$ \\
\hline Cantabria . & $3.525 .964,12$ & $4.138 .503,00$ \\
\hline Castilla y León.. & $14.954 .598,88$ & $13.501 .440,73$ \\
\hline Castilla-La Mancha & $3.763 .028,89$ & $6.476 .617,77$ \\
\hline Cataluña & $63.013 .963,87$ & $56.635 .208,26$ \\
\hline Comunidad de Madrid & $35.771 .587,42$ & $77.270 .725,92$ \\
\hline Comunitat Valenciana & $43.325 .367,88$ & $24.394 .901,57$ \\
\hline Extremadura & $1.463 .490,12$ & $347.282,12$ \\
\hline Galicia & $16.025 .752,92$ & $11.695 .345,05$ \\
\hline Murcia & $14.263 .834,99$ & $2.855 .267,40$ \\
\hline Navarra & $12.373 .677,40$ & $3.740 .842,33$ \\
\hline País Vasco & $23.625 .326,63$ & $22.180 .619,93$ \\
\hline La Rioja & $2.460 .668,16$ & $1.097 .758,90$ \\
\hline Ceuta & 263,57 & $111.317,27$ \\
\hline Melilla & 62,91 & $38.410,69$ \\
\hline
\end{tabular}




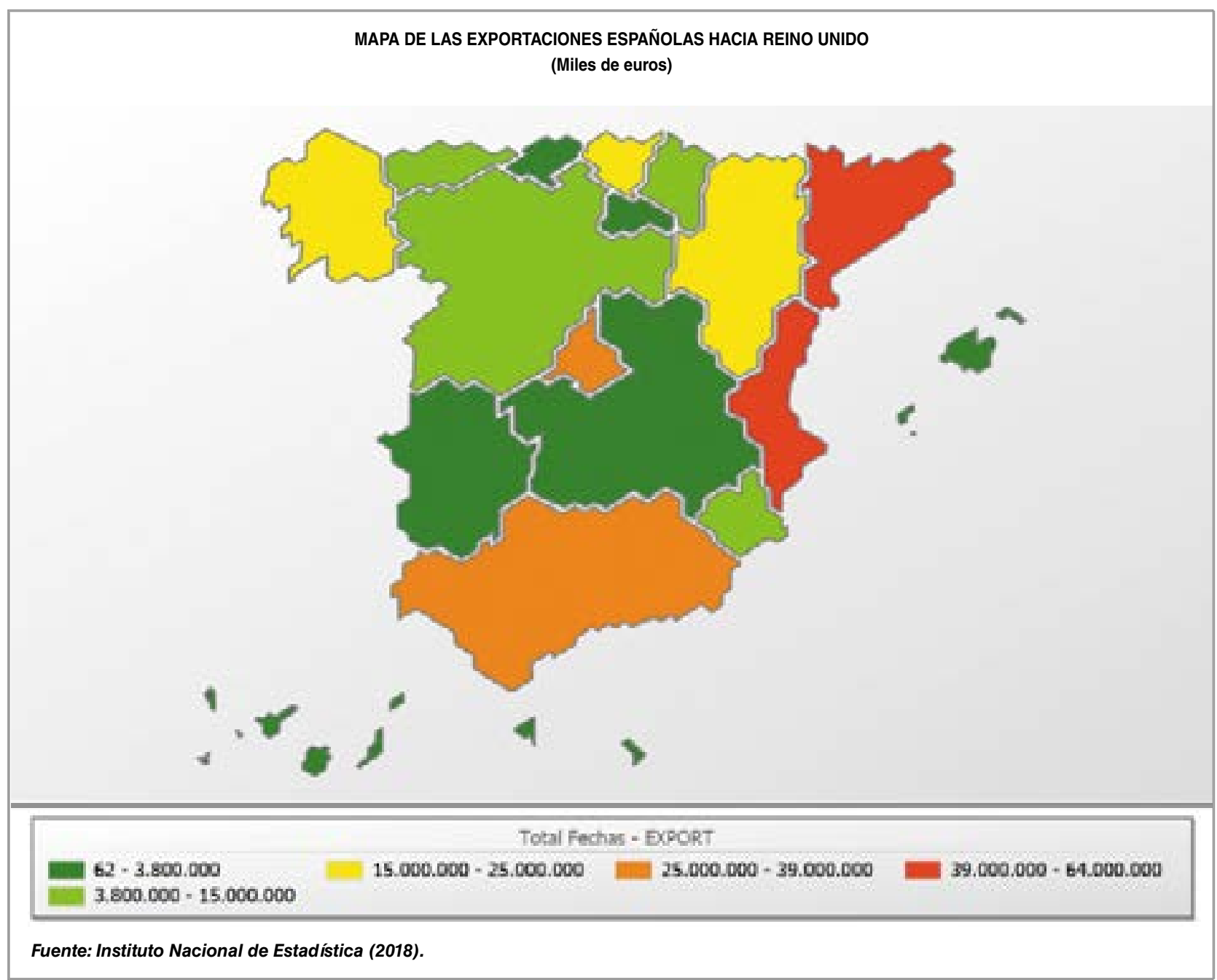

impacto del brexit se sentirá en comunidades como Madrid, Murcia, Comunitat Valenciana y Aragón.

Dentro de las exportaciones de servicios, el sector turismo es uno de los más perjudicados e incidirá sobre todo en Canarias e llles Balears, ya que representan más del 50 por 100 del total de los 15,5 millones de pernoctaciones británicas en España (cifra que hace que el sector turístico español ingrese mediante hoteles más de 14.000 millones de euros). Junto a ello, la depreciación de la libra golpea a los bolsillos de los ciudadanos británicos, reduciendo tanto el número de pernoctaciones en España como su gasto total, siendo estos ingresos difícilmente sustituibles por las dos comunidades autónomas.
Además de lo anterior, debemos tener en cuenta a la población británica que reside o veranea normalmente en España en sus segundas residencias, siendo la mayoría de ellos jubilados. A la espera de ver cuál será el acuerdo en materia de pensiones, la reducción del gasto de esta parte de la ciudadanía británica dañará a los ingresos de comunidades como Andalucía, Comunitat Valenciana, Canarias, Illes Balears y Murcia, donde representan hasta el 10 por 100 de la población extranjera.

Por otro lado, las comunidades autónomas que más realizan compras de bienes y servicios desde el Reino Unido son Comunidad de Madrid (77.270.725 miles de euros), Cataluña (56.535.208 miles de euros), Comunitat $\triangleright$ 
Valenciana (24.394.901 miles de euros), País Vasco (22.180.619 miles de euros) y Andalucía (13.007.232 miles de euros). Desde el centro peninsular, la Comunidad de Madrid importa principalmente productos farmacéuticos desde el Reino Unido por valor de más de 46.000 millones de euros, mientras que otros sectores como el sector de la cosmética (10.000 millones), el sector editorial (4.000 millones), el sector del plástico (3.800 millones) y el sector de las bebidas (2.500 millones) ocupan el segundo, el tercero, el cuarto y el quinto puesto, respectivamente, en la lista de sectores importadores de Reino Unido. En el caso de Cataluña, representaron el 3,47 por 100 del total importado, donde las semimanufacturas $(31,20$ por $100)$, el sector del automóvil (27,23 por 100) y el de los bienes de equipo (16,32 por 100) son los más activos, seguidos por la alimentación $(10,13$ por 100$)$ y las manufacturas de consumo (6,54 por 100), de acuerdo con datos del ICEX de 2015. Por otro lado, si recogemos los datos proporcionados por la Cámara de Comercio Valenciana, los principales sectores de importación británicos son el automovilístico (1.380 millones de euros), las frutas y hortalizas (216 millones de euros) y los productos cerámicos (168 millones de euros), seguidos del sector que más está creciendo en los últimos años: el sector ferroviario (100 millones de euros). Por parte de las estadísticas del Gobierno vasco, los principales sectores importadores de bienes y servicios procedentes de Reino Unido son los combustibles minerales, la fundición de hierro y acero y los reactores nucleares, por delante del sector de las energías renovables, el aeroespacial y la automoción. Por último, de acuerdo con la Junta de Andalucía, las importaciones andaluzas de Reino Unido más importantes son las pertenecientes a productos industriales y tecnológicos, ya que engloban más del 60 por 100 del total de las mismas, destacando los productos «medioambientales y de producción energética» $(34,35$ por 100 del total), mientras que en lo que se refiere a los bienes agroalimentarios (segundo grupo sectorial en importancia con un peso del 16,05 por 100) destacan los productos de origen vegetal $(62,23$ por 100 del total de los productos agroalimentarios).

Desde esta perspectiva, el brexit afectará bastante y con diferentes consecuencias a todas y cada una de las comunidades autonómicas. Si atendemos a una encuesta realizada por el Comité Europeo de las Regiones (CdR), donde hasta ocho regiones españolas participaron (Comunidad de Madrid, País Vasco, CastillaLa Mancha, Canarias, Murcia, Illes Balears, Comunitat Valenciana y Andalucía), aunque ya están empezando a hacerse visibles los efectos del brexit, será a partir del 29 de marzo de 2019 (fecha prevista para la materialización del brexit) cuando se verán las verdaderas consecuencias. El País Vasco pone de relieve que sus sectores más afectados serán la industria automovilística, la aeroespacial y la ferroviaria; la Comunidad de Madrid manifiesta su preocupación por el impacto del brexit sobre su industria hotelera y su comercio; Castilla-La Mancha afirma que su sector agroalimentario será el más perjudicado, sobre todo, por los recortes que puedan ocasionarse en los Fondos Sociales Europeos (FSE) y en los Fondos Europeos de Desarrollo Regional (FEDER); Canarias y Baleares manifiestan su preocupación por su sector turístico; Murcia pone de manifiesto que sufrirá recortes en sus ingresos procedentes tanto de su turismo como de las exportaciones de sus productos agroalimentarios; la Comunitat Valenciana pone el acento sobre sus exportaciones en general y sobre la pérdida de ingresos que generan los residentes británicos en su región; por último, $\triangleright$ 


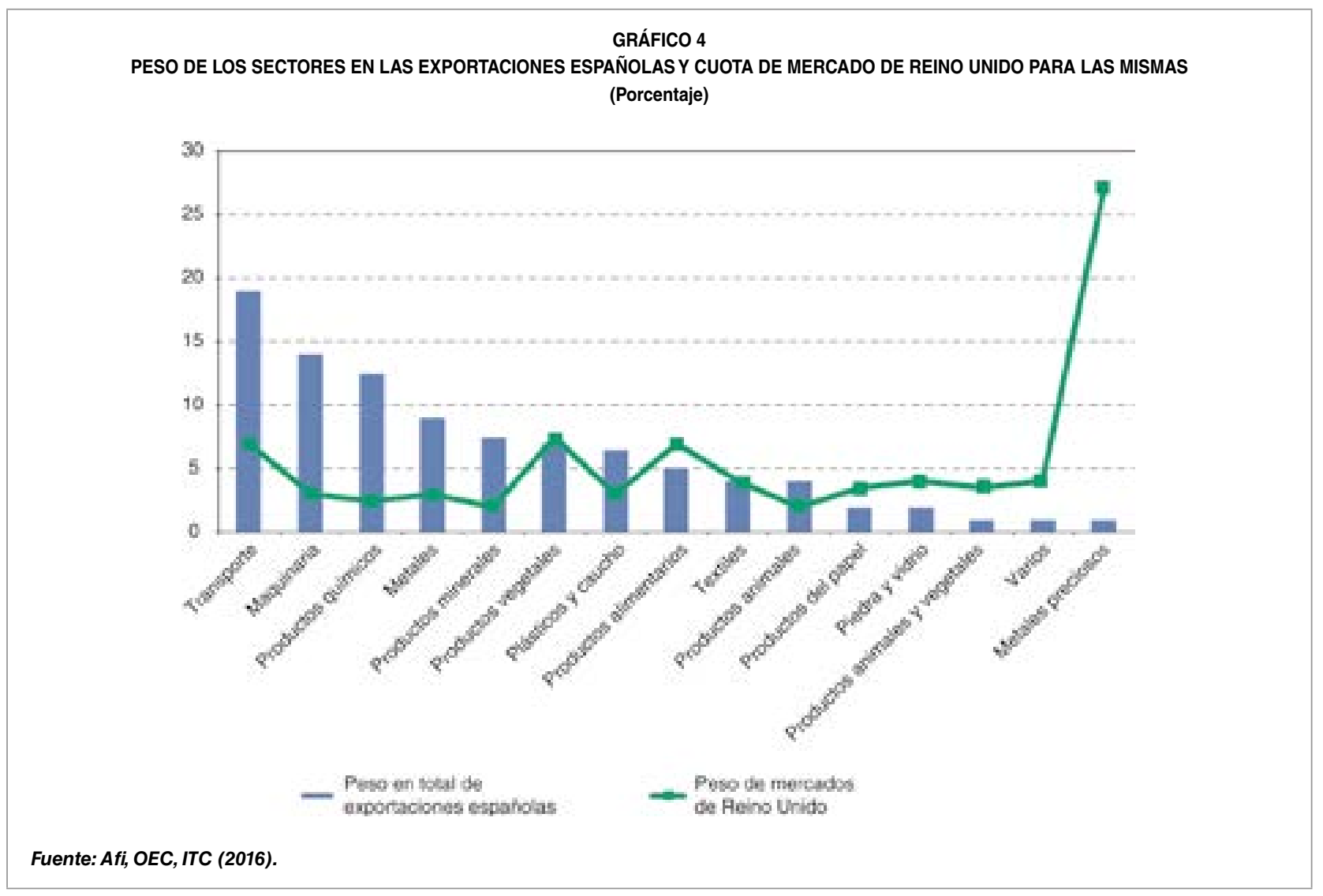

Andalucía acentúa la situación que viven y vivirán los ciudadanos residentes en su región y en Gibraltar, y el cruce de fronteras que hacen los mismos en una y otra dirección.

\subsection{Relaciones comerciales: sectores de actividad}

Desde la crisis de 2008, España y Reino Unido han reforzado sus relaciones comerciales como vía de crecimiento económico recíproco. En 2016, año del anuncio del brexit, las exportaciones españolas de bienes y servicios hacia Reino Unido continuaron con su crecimiento a pesar de una ralentización de las mismas durante la segunda mitad del año, llegando a 31 de diciembre con un saldo comercial bilateral favorable para España. Las exportaciones alcanzaron el montante total de $\mathbf{3 6 . 5 5 0}$ millones de euros, un 6,4 por 100 más que en 2015. Si procedemos a llevar a cabo este estudio en mayor detalle y ver qué sectores han sido los más activos en estas relaciones comerciales en el año del anuncio del brexit, el Gráfico 4 nos indica que, para el caso español, el sector de los transportes es el más activo en cuanto a exportaciones hacia el Reino Unido, seguido por el sector de la maquinaria, los productos químicos, los metales, los productos minerales y vegetales. A pesar de ello, el sector que mayor peso tiene en el mercado de Reino Unido son los metales preciosos, seguido por los productos vegetales, los productos alimenticios y los transportes.

La evolución de los intercambios totales comerciales en 2016 no pone de manifiesto la realidad que provocó el anuncio del brexit y la posterior depreciación de la libra esterlina, ya que existen dos comportamientos muy $\triangleright$ 




distintos en las dos mitades del año. Si durante la primera mitad de 2016 las exportaciones de bienes y servicios registraron un fuerte dinamismo con un incremento del 13 por 100 respecto al mismo periodo del año anterior (muy superior al crecimiento de las exportaciones hacia el conjunto de países de la UE, que fue del 5,6 por 100), la segunda mitad del año se caracterizó por una desaceleración de las mismas, que tuvo su continuidad durante el año 2017 con una caída del 5,7 por 100 respecto al total exportado en 2016, debido entre otras cosas al descenso de exportaciones en el sector del automóvil, contrastando con el aumento de las exportaciones españolas hacia el conjunto de la UE.

A pesar de estas cifras, hubo un sector que no sufrió con el anuncio del brexit: el sector turismo. De acuerdo con datos del Banco Central de España, durante el año 2016 llegaron a España 17,8 millones de turistas procedentes de Reino Unido, gastando un 12,8 por 100 más que en el año 2015 y alcanzando el total de 16.000 millones de euros, a pesar de la depreciación de la libra esterlina. Esta situación se sostuvo gracias a la inseguridad de otros destinos y potenciales rivales de España, impulsando las visitas de ciudadanos británicos a nuestro país.

Tras más de un año del anuncio del proceso del brexit, y aunque han caído las relaciones comerciales entre España y el Reino Unido, estas aún son importantes para ambos países. En 2017, el principal sector exportador español hacia las islas británicas fue el sector del automóvil, superando los 81.000 miles de euros, seguido por el sector de la maquinaria y aparatos mecánicos (21.600 miles de euros), aparatos y materiales eléctricos (17.600 miles $\triangle$ 
David de Matías Batalla
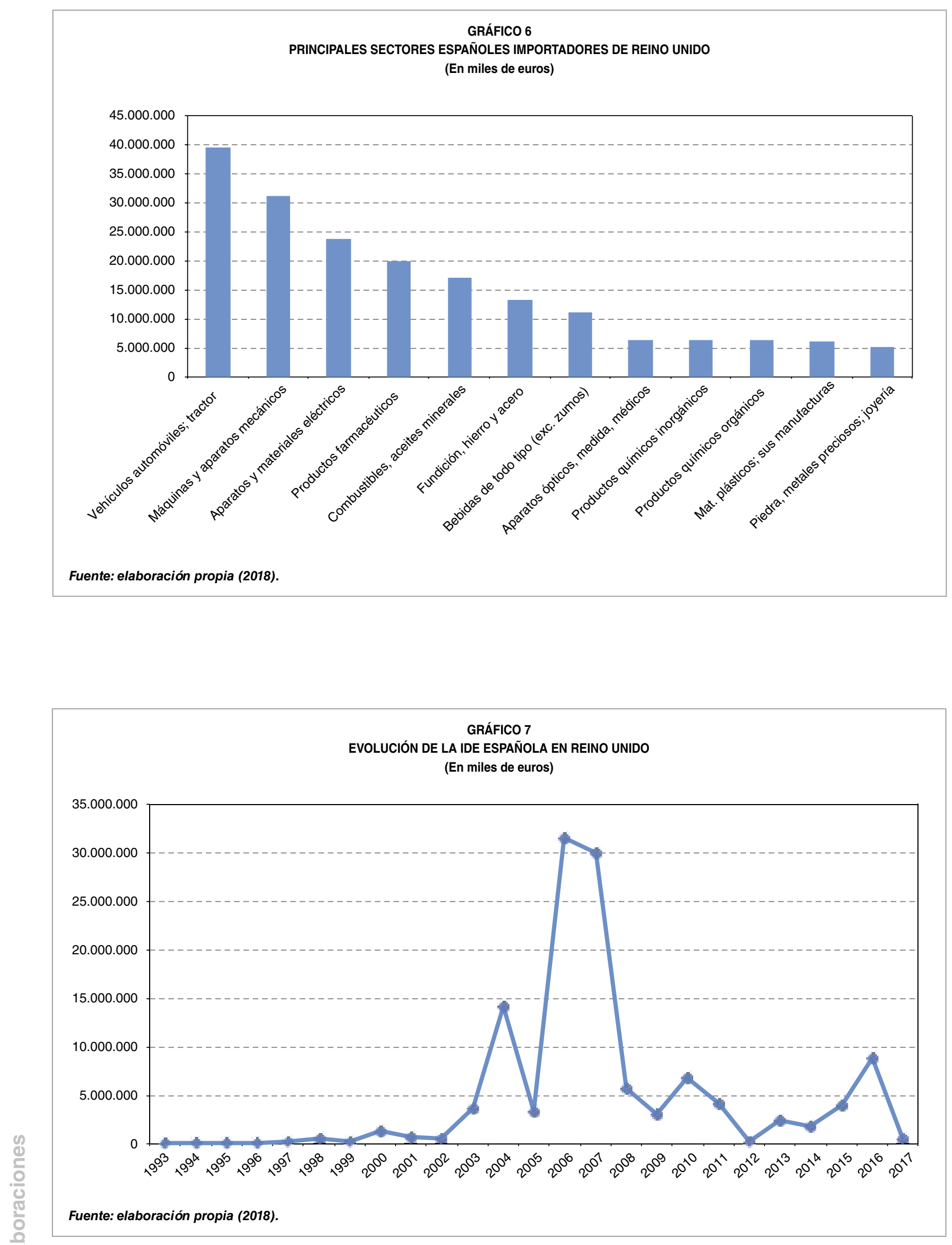
de euros), legumbres y hortalizas (14.500 miles de euros), el sector farmacéutico (12.600 miles de euros) y el sector frutícola (12.150 miles de euros).

Por el lado de las importaciones, es de destacar el notable papel bidireccional del sector del automóvil, que alcanza la cuantía de 39.600 miles de euros, seguido por las máquinas y aparatos mecánicos (31.100 miles de euros), los aparatos y materiales eléctricos $(23.700 \mathrm{mi}-$ les de euros), el sector farmacéutico (20.000 miles de euros) y los combustibles y aceites minerales (17.100 miles de euros).

\section{Inversiones directas extranjeras españolas en Reino Unido}

La inversión directa española en las islas británicas tuvo un montante residual durante toda la década de los noventa del pasado siglo, ya que fue la década del dorado latinoamericano para las empresas españolas, concentrando los países de América Latina la mayor parte de los flujos de inversión directa extranjera española. En el año 2000, con la llegada del euro, las preferencias de las empresas españolas cambiaron y empezaron a mirar más a los países de la zona euro y al Reino Unido, que, aunque no tiene el euro, disfruta hasta la salida oficial de la Unión Europa de total libertad de movimiento de capitales.

A partir del año 2000 se inicia una época en la que la tendencia de las inversiones españolas en el Reino Unido ha ido siendo mayor aunque con altibajos en su evolución, pero que a pesar de estos altibajos (debido a grandes operaciones empresariales) ha hecho que, en la actualidad, Reino Unido sea el principal receptor de inversión directa española de España. El stock total de inversión española en Reino
Unido alcanza la cifra de 124.310 millones de euros, siendo los principales años de inversión 2006 (31.487 millones de euros), 2007 (30.043 millones de euros), 2004 (14.242 millones de euros) y 2016 (8.904 millones de euros).

Antes de la crisis de 2008, durante el periodo 2003-2008, la inversión española en las islas británicas creció debido a una serie de grandes operaciones empresariales. Entre las operaciones más relevantes de inversión directa española en las islas británicas destacan las llevadas a cabo por las grandes multinacionales, tanto en volumen como en número de operaciones, lideradas por grandes operaciones de adquisición o de fusión. Entre las mismas, sobresalen por encima de todas las adquisiciones realizadas por el Banco de Santander (Abbey y Alliance \& Leicester), Telefónica (O2), Ferrovial (BBA), Iberdrola (Scottish Power) y Agbar (British Water), además de la operación de fusión entre Iberia y British Airways, que dio lugar a la actual IAG.

Como puede apreciarse en el Gráfico 7, tras la crisis y un descenso pronunciado de las inversiones españolas en Reino Unido, la tendencia desde 2012 es claramente positiva, siendo el reflejo del aumento de las empresas españolas de sus posibilidades en las islas y de la recuperación de la propia crisis. A pesar de esta evolución positiva, el anuncio del brexit parece haber congelado la confianza y las expectativas de los empresarios españoles, ya que, durante los primeros tres trimestres, las inversiones españolas en Reino Unido cayeron hasta la cuantía de 570.912 .000 euros, terminando con la evolución positiva.

En lo que se refiere a los destinos de origen de las inversiones directas españolas en Reino Unido (Gráfico 8), destaca por encima de todo el sector de las telecomunicaciones (37.500 $\triangleright$ 
David de Matías Batalla

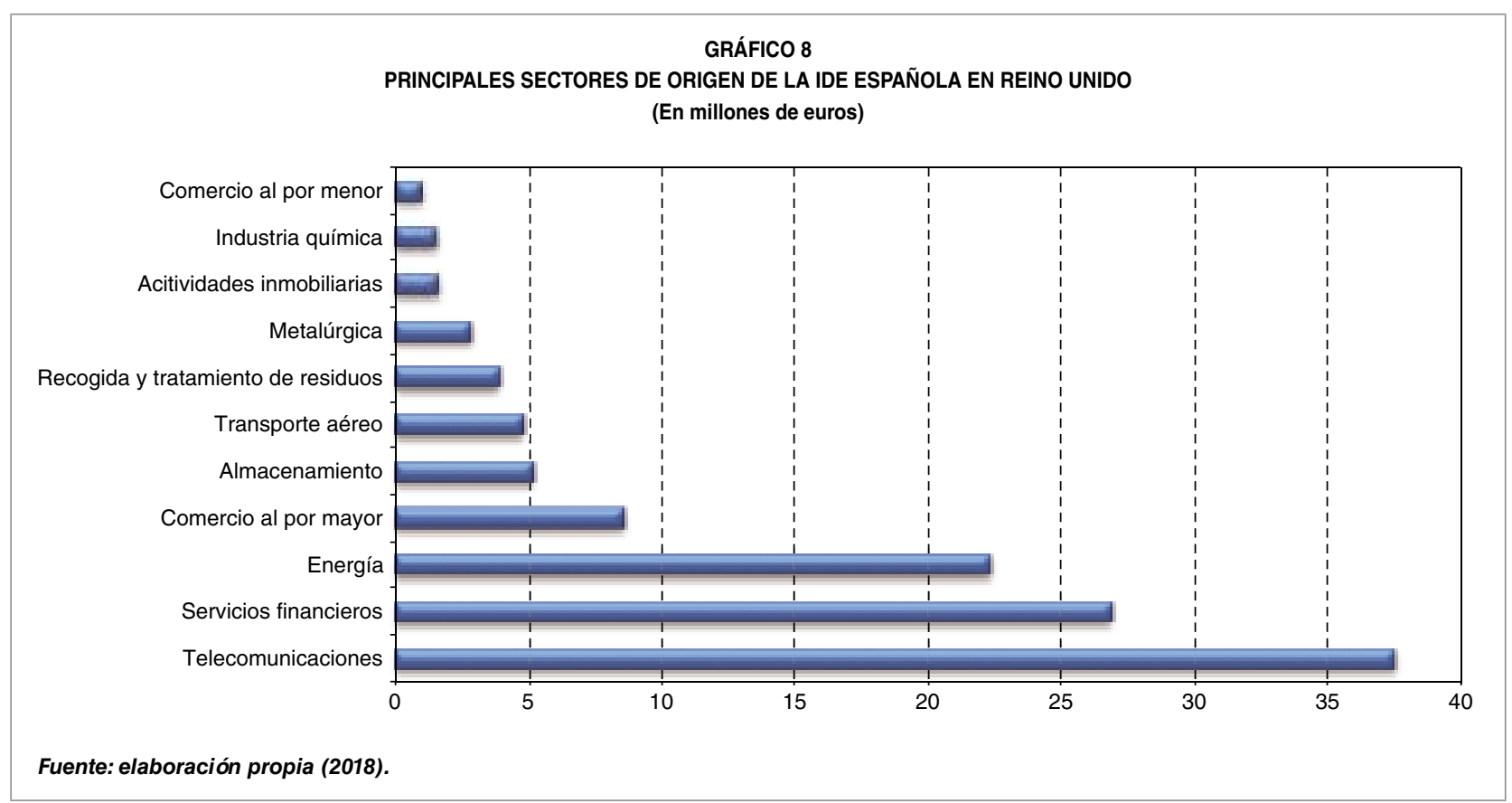

millones de euros), los servicios financieros (26.800 millones de euros) y el sector energético (22.300 millones de euros), por delante de otros sectores como el comercio al por mayor (8.500 millones de euros), la logística (5.100 millones de euros) oeltransporte aéreo (4.700 millones de euros).

Actualmente, cerca de trescientas empresas españolas, la mayoría de ellas de mediano tamaño, tienen una parte de su negocio en $\triangleright$

GRÁFICO 9

EVOLUCIÓN DE LA IDE BRITÁNICA EN ESPAÑA

(En miles de euros)

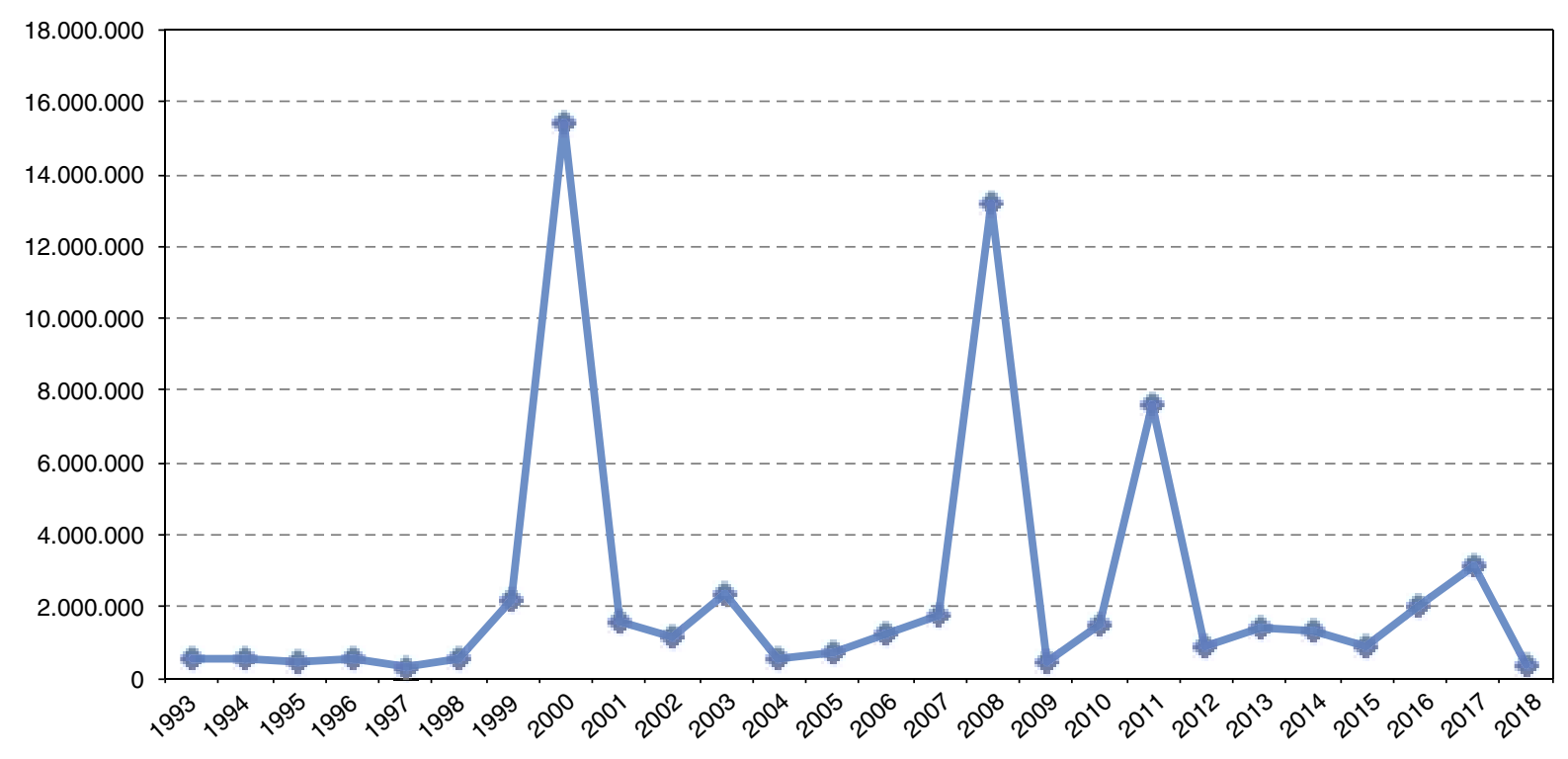

Fuente: elaboración propia (2018). 


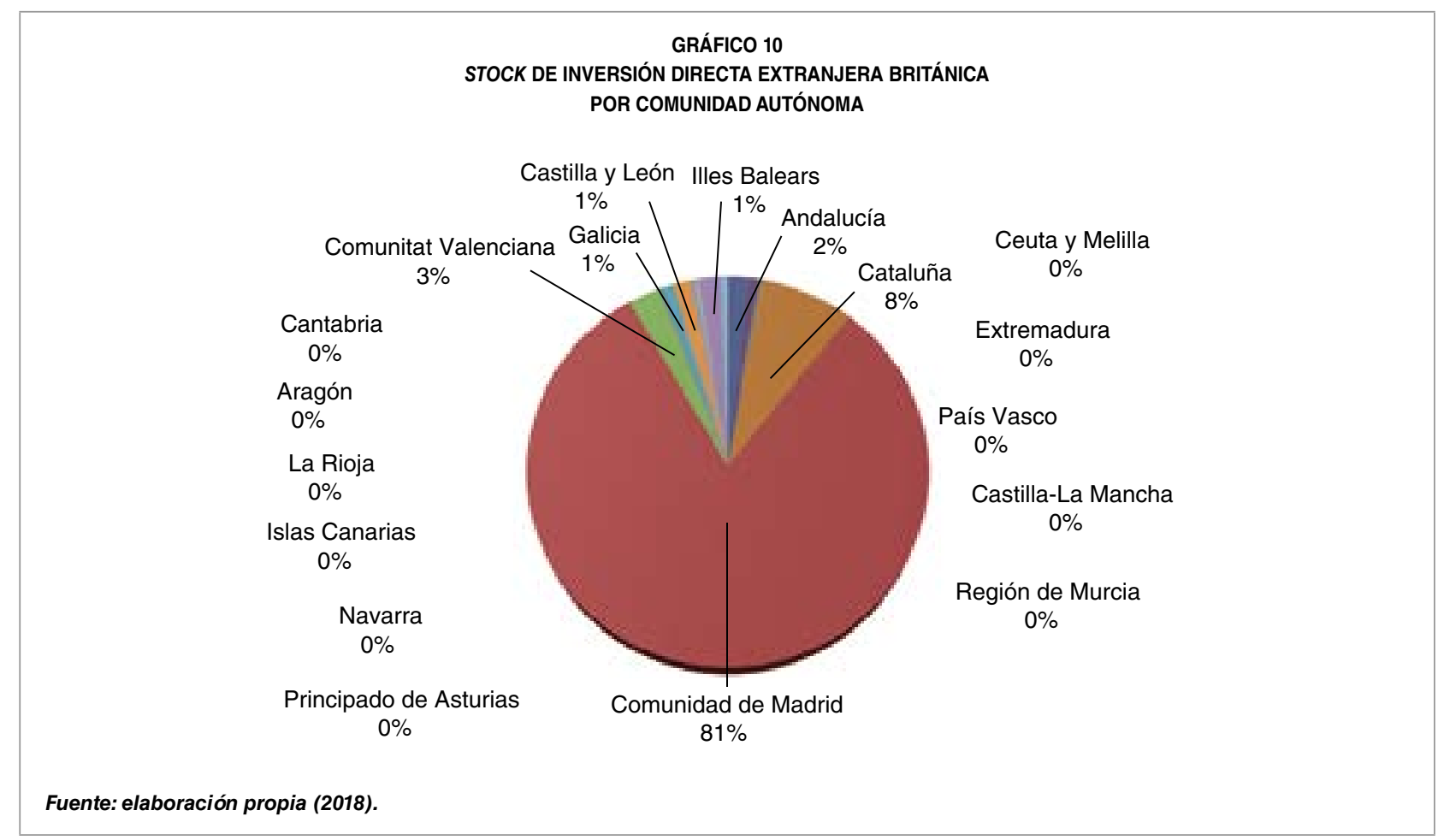

Reino Unido y cuentan con una sede física en el mercado británico. El 40 por 100 de ellas tiene su sede social en Londres. Según el directorio de empresas españolas establecidas en Reino Unido, elaborado por el ICEX, hay 261 empresas españolas instaladas en el país, que operan fundamentalmente en los sectores agroalimentario; medioambiente y producción energética; infraestructuras, construcción civil e ingeniería; productos farmacéuticos; transporte, logística y comunicaciones y bienes de consumo y servicios.

\section{Inversiones directas extranjeras británicas en España}

La inversión directa española en Reino ha mantenido desde la década de los noventa una tendencia en la que cada año las empresas españolas mantenían inversiones por debajo de los 2.000 millones de euros, con una tendencia positiva desde 2004 hasta 2008, manteniéndose estable y a niveles de siempre durante y después de la última crisis económica. El total de la inversión británica acumulada desde 1993 (fecha en la que se empiezan a tener datos oficiales procedentes del ICEX) en España asciende hasta la cuantía de 62.826 millones de euros. Tan solo en dos años, 2001 y 2005, las desinversiones por parte de Reino Unido superaron a las inversiones brutas.

En el Gráfico 9 se puede visualizar esta tendencia temporal, en la que destaca la inversión en tres años claves, 2000, 2008 y 2011, y en la que las empresas británicas invirtieron 15.441 millones de euros, 13.218 millones de euros y 7.631 millones de euros, respectivamente. Las razones principales de estos picos de inversión fueron las operaciones realizadas por las empresas de las telecomunicaciones en 2000 , la compra de Altadis por Imperial Tobacco en 2008 y la fusión entre Iberia y British Airways en 2011. Lejos de sufrir un retroceso por el $\triangleright$ 


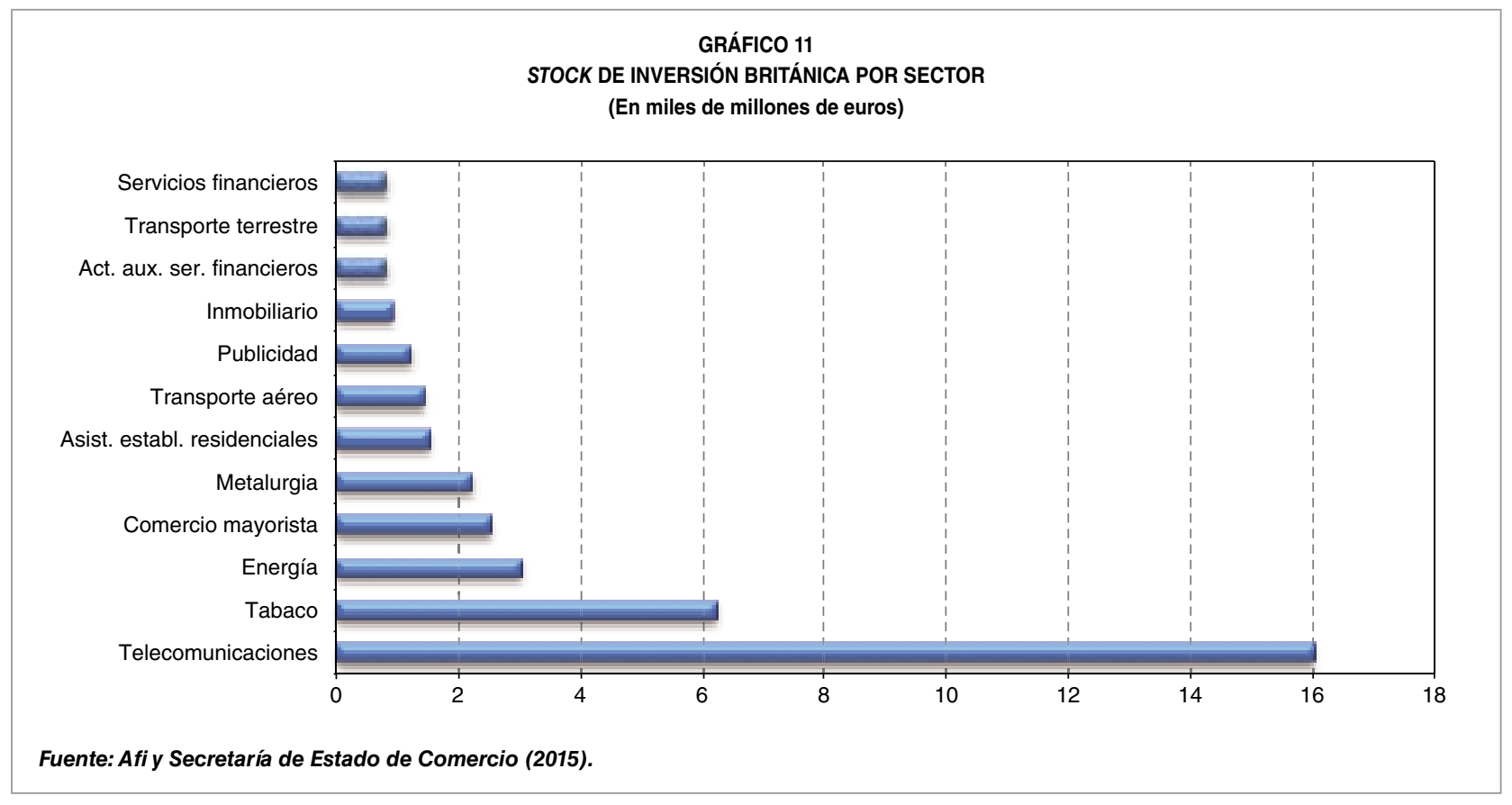

brexit, el atractivo de España para las empresas británicas se hace patente desde el año 2014, observándose una tendencia positiva y haciendo que, a día de hoy, Reino Unido sea el país europeo que mayor inversión directa realiza en España.

Estas cifras están quedando a su vez reforzadas por declaraciones a más alto nivel institucional, como las que realizó recientemente Christopher Dottie, presidente de la Cámara de Comercio Británica en España, realzando la importancia de la relación que hay entre España y Reino Unido, a pesar de los convulsos momentos políticos que vivimos en ambos lados. De acuerdo con los datos aportados por Analistas Financieros Internacionales (Afi), las empresas británicas representan el 12,8 por 100 de la inversión total en España, superada solamente por las empresas estadounidenses y un punto por encima de las compañías italianas.

Además, analizando los estudios de Afi, podemos descubrir que el stock de inversión directa británica en España se sigue concentrando en las comunidades de Madrid, País Vasco y
Cataluña, siendo los sectores de las telecomunicaciones, el tabaco y el sector energético los que lideran tal inversión. Si nos adentramos en los datos proporcionados por el ICEX, Madrid es la principal comunidad autónoma receptora de inversión directa procedente de Reino Unido, acumulando el 81 por 100 del total de la inversión británica, por delante de Cataluña (8 por 100), Comunitat Valenciana (3 por 100), Andalucía (2 por 100) y País Vasco (2 por 100).

Por sectores, las telecomunicaciones son el principal sector beneficiado por las inversiones británicas, con 16.000 millones de euros de stock, seguido por el tabaco (más de $6.000 \mathrm{mi}$ llones de euros), el energético (3.000 millones de euros) y el comercio mayorista (2.500 millones de euros).

\section{Conclusiones}

Un año y medio después de que los ciudadanos británicos votasen a favor de abandonar la Unión Europea, se puede observar que $\triangleright$ 
existe una evolución más débil tanto en las exportaciones como en las importaciones con Reino Unido, pero que se hace más palpable en las importaciones. En los años posteriores de la crisis financiera y anteriores al referéndum, las relaciones comerciales entre ambos países se fortalecieron y tanto las exportaciones como las importaciones estaban creciendo a tasas muy elevadas, a niveles superiores a los de hace diez años. De hecho, durante 2015 y la primera mitad de 2016, las exportaciones españolas a Reino Unido crecieron un 10,4 por 100 y un 11,3 por 100 respectivamente. Tras el referéndum, el crecimiento desapareció y su evolución fue del $-1,1$ por 100 durante la segunda mitad de 2016 y del -0,9 por 100 en 2017. Por otro lado, las importaciones no se han visto tan afectadas por el brexit, ya que mantienen ritmos de crecimiento positivos, pero este crecimiento sí que es verdad que se ha ralentizado, probablemente provocado por la actual incertidumbre.

A nivel de inversiones, el brexit ha desencadenado que muchas empresas hayan decidido no invertir y ha hecho que otros posibles acuerdos entre empresas españolas y británicas se hayan frustrado. La activación del artículo 50 del Tratado de Lisboa, por parte de Reino Unido, está haciendo que la incertidumbre sembrada cree dudas sobre las inversiones a ambos lados.

Lo que sí que parece que no va a cambiar a pesar del brexit es el turismo. Durante el año 2016 fueron 17,8 millones de turistas los que llegaron desde Reino Unido a España, consiguiendo gastar 16.000 millones de euros, un 12,8 por 100 más que en 2015. Sin embargo, este crecimiento se ha visto favorecido por la inseguridad e inestabilidad de otros países que compiten con España por los turistas británicos, por lo que las cifras podrían ser menores una vez que tales países recuperen su atractivo.

\section{Bibliografía}

[1] BOURGUIGNON, F. et al. (2002). «Making sense of Globalization». CEPR Policy Paper, n.․ 8.

[2] CANALS, C. y NOGUER, M. (2007). «La inversión extranjera directa en España: ¿Qué podemos esperar del tigre celta?». Documento de Economía de la Caixa, n.․ 7, pp. 5-29.

[3] CÁMARAS DE COMERCIO DE ESPAÑA (2007). Internacionalización de la empresa española. Cooperación Empresarial e Inversión exterior. Madrid.

[4] CEOE (2016). Brexit, situación actual y exposición de la economía española a Reino Unido. Departamento de Asuntos Económicos y Europeos. Madrid.

[5] CHISLETT, W. (2003). La inversión española directa en América Latina: retos y oportunidades. Real Instituto Elcano de Estudios Internacionales y Estratégicos. Madrid.

[6] DE MATÍAS BATALLA, D. (2015). «Debe ser revisado el paradigma ecléctico ante las nuevas formas de hacer negocios internacionales?». Boletín Económico: ICE, n. 3060, pp. 39-50.

[7] DÍAZ VÁZQUEZ, R. (2003). «Las teorías de la localización de la inversión extranjera directa: Una aproximación». Revista Gallega de Economía, vol. 12, n. 1, pp. 1-12.

[8] DUNNING, J.H. (1994). "Re-evaluating the benefits of foreign direct investment». Journal of International Business Studies, ‥ $=26$, pp. 461-491.

[9] DURÁN HERRERA, J.J. (2000). «La inversión extranjera en el siglo XX. La persistente multinacionalización de la empresa». Revista de Economía Mundial, n.ํㅜ 3, pp. 121-148.

[10] DURÁN HERRERA, J. J. (2003). «Veinticinco años de inversión directa española en el exterior. 1978-2003. Una senda de crecimiento». Economía Industrial, n. ㅇ 350, pp. 147-154.

[11] DURÁN HERRERA, J. J. et al. (2007). «Inversión directa en el exterior, crecimiento económico y exportaciones de la economía española». Revista ICE, n.. 839, pp. 35-54.

[12] ESRCCENTREFORBUSINESSRESEARCH, (2008). «FDI, the location advantages of countries and the competitiveness of TNCS: US FDI in professional service industries". University of Cambridge Working Paper, n. 128. 
[13] FERREIRO APARICIO, J.; GÓMEZ VEGA, J. y RODRÍGUEZ GONZÁLEZ, C. (2009). Estabilidad de los flujos de inversión extranjera directa: el caso de las inversiones españolas en Latinoamérica. Departamento de Economía Aplicada V. Universidad del País Vasco.

[14] FMI (2008). «International Investment Position». Capítulo 7 del informe Balance of payments and international investment position manual. Nueva York.

[15] GALÁN ZAZO, J. I. y González Benito, J. (2001). «Factores explicativos de la inversión directa española en el exterior». Revista ICE, n. -794 , pp. 103-122.

[16] GALÁN ZAZO, J. I.; GONZÁLEZ BENITO, J. y ZÚÑIGA VICENTE, J. (2007). «Factors determining the location decisions of Spanish MNEs: An analysis based on the investment development path». Journal of International Business Studies, vol. 38, n.․․ 6, pp. 975-997.

[17] ICEX (2010). Internacionalización, empleo y modernización de la economía española. Madrid.
[18] ICEX (2017). Informe y Comercio entre España y Reino Unido. Londres.

[19] KPMG (2017). La empresa española ante el brexit. Madrid.

[20] LÓPEZ DUARTE, C. y GARCÍA CANAL, E. (2002). «La inversión directa de las empresas españolas en Latinoamérica». Revista Asturiana de Economía, n.․․ 23, pp. 27-45.

[21] OBSERVATORIO DE LA EMPRESA MULTINACIONAL ESPAÑOLA (2008). La expansión de la multinacional española: estrategias y cambios organizativos. Madrid.

[22] RODRÍGUEZ GONZÁLEZ, C.; GÓMEZ VEGA, C. y FERREIRO APARICIO, J. (2005). «Panorámica de los estudios sobre inversión extranjera directa». Economiaz, n.ำ5, pp. 284-301.

[23] RONDEROS TORRES, C. (2010). «Inversión extranjera y competitividad». Revista Globalización, Competitividad y Gobernabilidad. GCG Georgetown University, vol. 4, n.ำ 2, pp. 72-87.

[24] SANTISO GUIMARAS, J. (2007). «La internacionalización de las empresas españolas: Hitos y retos». Revista ICE, n.․ 839, pp. 89-102. 

ISSN 0214-8307

\section{SUSCRIPCIÓN ANUAL}

\begin{tabular}{|c|c|c|c|}
\hline \multicolumn{3}{|c|}{ BOLETÍN ECONÓMICO DE INFORMACIÓN COMERCIAL ESPAÑOLA (12 NÚMEROS) } \\
\hline & $\begin{array}{c}\text { ESPAÑA } \\
\mathbf{1} \text { año }\end{array}$ & $\begin{array}{c}\text { UNIÓN EUROPEA } \\
\mathbf{1} \text { año }\end{array}$ & $\begin{array}{c}\text { RESTO DEL } \\
\text { MUNDO } \\
1 \text { año }\end{array}$ \\
\hline SUSCRIPCIÓN & $65,00 €$ & $85,00 €$ & $85,00 €$ \\
\hline $\begin{array}{c}\text { Gastos de envío } \\
\text { España }\end{array}$ & $5,76 €$ & $24,36 €$ & $30,00 €$ \\
\hline $\begin{array}{c}\text { Más 4\% de IVA. } \\
\text { Excepto Canarias, Ceuta y Melilla }\end{array}$ & $2,83 €$ & & $115,00 €$ \\
\hline TOTAL & $73,59 €$ & $109,36 €$ & \\
\hline & & & \\
\hline
\end{tabular}

\section{EJEMPLARES SUELTOS}

\begin{tabular}{|c|c|c|c|}
\hline BOLETÍN ECONÓMICO & DE INFORMACIÓN & COMERCIAL ESPAÑOL & \\
\hline & $\begin{array}{l}\text { ESPAÑA } \\
1 \text { ejemplar }\end{array}$ & $\begin{array}{l}\text { UNIÓN EUROPEA } \\
1 \text { ejemplar }\end{array}$ & $\begin{array}{l}\text { RESTO DEL } \\
\text { MUNDO } \\
1 \text { ejemplar }\end{array}$ \\
\hline NÚMERO SUELTO & $7,00 €$ & $9,00 €$ & $9,00 €$ \\
\hline $\begin{array}{l}\text { Gastos de envío } \\
\text { España }\end{array}$ & $0,48 €$ & $2,03 €$ & $2,50 €$ \\
\hline $\begin{array}{l}\text { Más } 4 \% \text { de IVA. } \\
\text { Excepto Canarias, Ceuta y Melilla }\end{array}$ & $0,30 €$ & & \\
\hline TOTAL & $7,78 €$ & $11,03 €$ & $11,50 €$ \\
\hline \multirow[t]{2}{*}{ BOLETÍN ECONÓMICO } & DE INFORMACIÓN & COMERCIAL ESPAÑOL & \\
\hline & $\begin{array}{l}\text { ESPAÑA } \\
1 \text { ejemplar }\end{array}$ & $\begin{array}{l}\text { UNIÓN EUROPEA } \\
1 \text { ejemplar }\end{array}$ & $\begin{array}{c}\text { RESTO DEL } \\
\text { MUNDO } \\
1 \text { ejemplar }\end{array}$ \\
\hline $\begin{array}{l}\text { NÚMERO SUELTO } \\
\text { EXTRAORDINARIO }\end{array}$ & $12,00 €$ & $15,00 €$ & $15,00 €$ \\
\hline Gastos de envío España & $0,48 €$ & $2,03 €$ & $2,50 €$ \\
\hline $\begin{array}{c}\text { Más 4\% de IVA. } \\
\text { Excepto Canarias, Ceuta y Melilla }\end{array}$ & $0,50 €$ & & \\
\hline TOTAL & $12,98 €$ & $17,03 €$ & $17,50 €$ \\
\hline
\end{tabular}

\section{DATOS}

Nombre y apellidos

Empresa

Domicilio

D.P.

N.I.F.

Teléf.

Email

\section{DATOS DEL EDITOR:}

NIF:S2800568D

Transferencia a la cuenta de ingresos por venta de publicaciones del Ministerio de Economía y Competitividad.

IBERCAJA. Calle Alcalá 29. 28014 MADRID (ESPAÑA) CÓDIGO CUENTA CLIENTE: 2085-9252-07-0330598330 CÓDIGO BIC DE IBERCAJA: CAZRES2Z

IBAN: ES47 2085-9252-07-0330598330

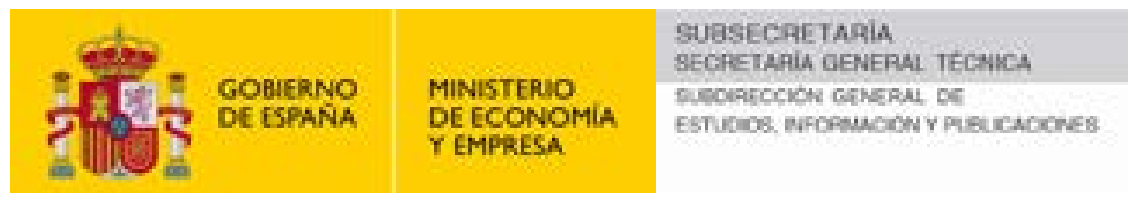

Suscripciones y ventas por correspondencia:

Paseo de la Castellana, $1628^{\text {a }}$ Planta 28046 Madrid. Teléfono 916037993 / 97

Suscripciones a través de la página web del Ministerio de Industria, Comercio y Turismo distribucionpublicaciones@mineco.es 


\section{Información Comercial Española \\ Revista de Economía}

6 números anuales

Artículos originales sobre un amplio espectro de temas tratados desde

una óptica económica, con especial referencia a sus aspectos internacionales
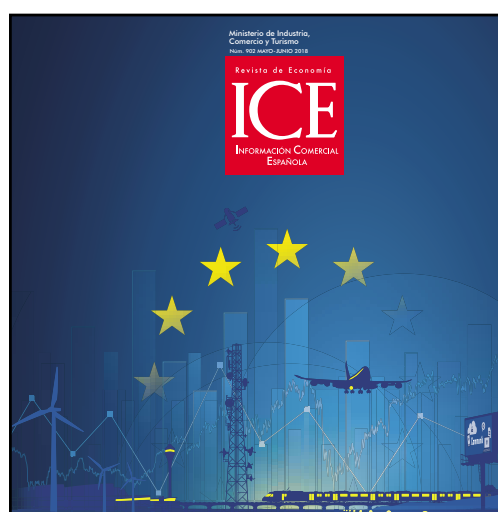

MERCADO INTERIOR EUROPEO 25 AÑOS DESPUÉS
Boletín Económico de Información Comercial Española

\section{2 números anuales}

Artículos y documentos sobre economía española, comunitaria e internacional, con especial énfasis en temas sectoriales $\mathrm{y}$ de comercio exterior

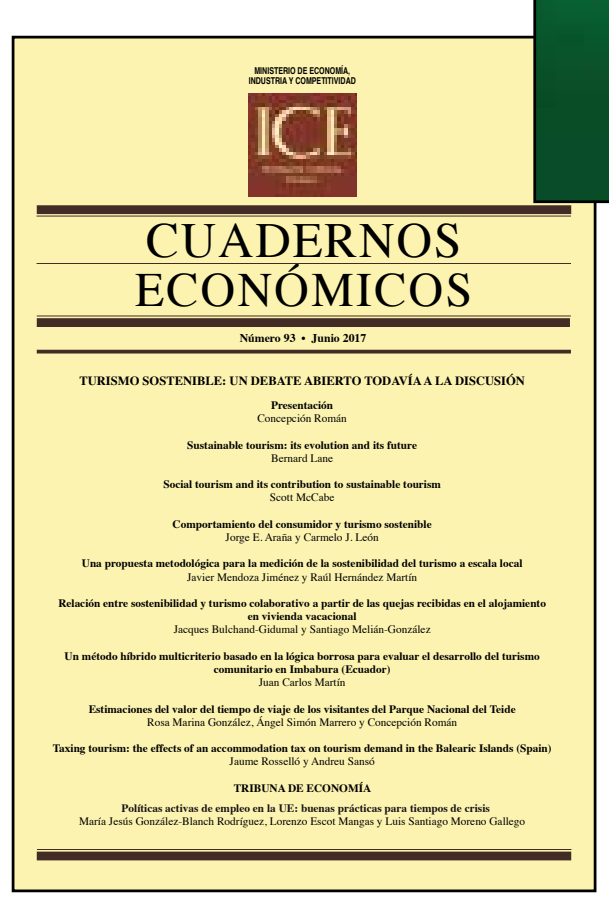

\section{Cuadernos Económicos de ICE}

2 números anuales

Artículos de economía teórica y aplicada y métodos cuantitativos, que contribuyen a la difusión y desarrollo de la investigación 


\section{NORMAS DE ESTILO DE PUBLICACIÓN}

La persona o personas interesadas en presentar un artículo para su publicación en el Boletín de Información Comercial Española (BICE) deberán enviar el artículo en formato Microsoft Word a la dirección de correo electrónico revistasice.sscc@comercio.mineco.es

El documento debe cumplir las siguientes características:

1. Ser material original no publicado ni presentado en otro medio de difusión.

2. La extensión total del trabajo (incluyendo cuadros, gráficos, tablas, notas, etcétera) no debe ser inferior a 15 páginas ni superior a 20. La fuente será Times New Roman, tamaño 12 y espaciado doble. Estar paginado en la parte inferior derecha de cada página.

3. En la primera página se hará constar el título del artículo que deberá ser breve, claro, preciso e informativo y la fecha de conclusión del mismo. Nombre y dos apellidos del autor o autores, filiación institucional, dirección, teléfono y correo electrónico de cada uno de ellos, así como la forma en que desean que sus datos aparezcan.

4. En la segunda página del texto se incluirá:

- El título.

- Un resumen del trabajo con una extensión máxima de 10 líneas con la siguiente estructura: objetivo, método y principal resultado o conclusión.

- De 2 a 6 palabras clave que no sean coincidentes con el título.

- De 1 a 5 códigos de materias del Journal of Economic Literature (clasificación JEL) para lo cual pueden acceder a la siguiente dirección electrónica:

https://www.aeaweb.org/jel/guide/jel.php

5. En las siguientes páginas se incluirán el texto, la información gráfica y la bibliografía con la siguiente organización.

- Se incluirá, por este orden, introducción, desarrollo, conclusiones y bibliografía y anexos si los hubiera. Los apartados y subapartados se numerarán en arábigos respondiendo a una sucesión continuada utilizando un punto para separar los niveles de división, según el siguiente modelo:

\section{Título del apartado}

\subsection{Título del apartado}

1.1.1. Título del apartado

\section{Título del apartado}

- Las notas de pie de página irán integradas en el texto y su contenido debe estar al final de su misma página en tamaño 10 y espacio sencillo.

- En un archivo Excel independiente se incluirá la representación gráfica (cuadros, gráficos, diagramas, figuras, etc.), que debe llevar título, estar numerada y referenciada en el texto. En la parte inferior se incluirá la fuente de información y/o notas aclaratorias.

- Las citas de libros y artículos en el texto, se indicarán entre paréntesis con el apellido del autor y el año. Ej.: (Martínez, 1991).

- Las referencias a siglas deben ir acompañadas, en la primera ocasión en que se citen, de su significado completo.

- La bibliografía se ordenará alfabéticamente siguiendo las normas de la American Psychological Association (Harvard-APA): http://cibem.org/paginas/img/apa6.pdf

Libros

APELLIDOS, A.A. (año de publicación). Título del libro (edición) (volumen). Ciudad: Editorial.

Artículo en revista científica

APELLIDOS, A.A. (año de publicación). «Título del artículo». Título de la revista, volumen (número), números de páginas.

Documento en línea

APELLIDOS, A.A. u ORGANISMO (año, mes de publicación). Título, [en línea]. Ciudad: Editorial. Disponible en:

http://cenamb.rect.ucv.ve/siamaz/dicciona/canaima/canaima2.htm [Recuperado: 2000, 3 de junio].

Los artículos publicados estarán disponibles en www.revistas/CE.com 
